\title{
An Investigation of Condensation Heat Transfer of Dowtherm A in Polymer Solidification
}

\author{
Bora Yazgan ${ }^{1}$, Erdem Gorgun ${ }^{1}$, Mert Patkavak ${ }^{2}$, Murat Gokten ${ }^{2}$ \\ ${ }^{1}$ SDM Research \& Development \\ Teknopark/Pendik, Istanbul, 34906, Turkey \\ b.yazgan@sdmresearch.com, e.gorgun@sdmresearch.com \\ ${ }^{2}$ KORDSA Teknik Tekstil A.S., \\ Alikahya/Izmit, Kocaeli, 41310, Turkey \\ mert.patkavak@kordsa.com; murat.gokten@kordsa.com
}

\begin{abstract}
Polymer which is used in tire cord manufacturing, is transferred with jacketed transfer line and heating box to provide thermal stability of the system after extrusion process. The heating box is heated with vapor phase Dowtherm-A to compensate the heat loss of the polymer. In order to increase heat transfer on the condensation surfaces, reducing the thickness of condensed fluid film is essential. In this study, inlet mass flow rate of Dowtherm-A was investigated with steady state analyses. Results show that fluid moves through polymer pipes for higher inlet mass flow rate while it loses its energy and faces towards solidification chamber for lower inlet mass flow. Required Dowtherm-A mass flow for heat equilibrium at $300^{\circ} \mathrm{C}$ was calculated $0.0035 \mathrm{~kg} / \mathrm{s}$ for this system. In order to understand the effect of surface inclination over fluid film thickness two different solidification chamber designs were investigated. Heat transfer rate is improved by lowering the fluid film thickness with inclined top surface in comparison to flat top surface. Therefore, heat transfer rate of solidification chamber of inclined top design is $\% 3.5$ higher than flat top design. It was also observed that approximately $\% 46,1$ of the heat is transferred to solidification chamber and \%3,9 of the heat transferred to polymer pipes, whereas another half of the heat is lost due to heat transfer with ambient air. Total heat transfer in condensation surfaces was calculated as 1008 Watt for the inclined top design.
\end{abstract}

Keywords: Dow Heating Box, Tire Cord Manufacturing, Dowtherm-A, Condensation, Two-Phase CFD Analysis, Inclined Condensation Surface

\section{Introduction}

Dowtherm-A fluid is utilized in heat transfer processes and composed of two organic components which are, biphenyl $\left(\mathrm{C}_{12} \mathrm{H}_{10}\right)$ and diphenyl oxide $\left(\mathrm{C}_{12} \mathrm{H}_{10} \mathrm{O}\right)$. Since the vapor pressure of these components are approximately same, the Dowtherm-A fluid can be considered as a single compound fluid. It can be utilized from $15^{\circ} \mathrm{C}$ up to $400^{\circ} \mathrm{C}$, and from 1 bar to 10.6 bar in industrial heat transfer applications. Apart from the vapor phase heating, Dowtherm-A provides heating also in liquid phase. Viscosity, stability, freeze point and vapor pressure are four significant specifications of Dowtherm-A fluid that govern the heat transfer behaviour. Heating applications with the vapor phase Dowtherm-A have some benefits over the liquid Dowtherm-A systems, since natural circulation of the condensed vapor under the effect of gravity without using pumping device is possible [1].

Keeping the polymer temperature at desired level is quite significant. It has a prominent effect on structure of the polymer and eventually affects the physical properties of the thread. The heat transfer takes place at the saturation temperature of the gas phase Dowtherm-A. Hence, temperature of the system can be controlled precisely. The heat transfer rate per unit mass of heat medium is much more for the systems using vapor phase Dowtherm-A at low pressure values. According to these advantages, Dowtherm-A heat transfer fluid is used for in this study.

Condensation may occur either in dropwise or film condensation. Regardless it is dropwise or film, heat resistance of condensation increases as the fluid film thickens. Therefore, reducing the thickness of condensation increases heat transfer rate. Another way to increase heat transfer is using surface coatings that inhibit wetting [2].

Two-phase cycle provides high heat transfer rate between the surfaces even at a small temperature gradients [3]. Twophase Dowtherm-A was investigated and heat transfer performance was improved with inclination angle of 5-degree for a 
horizontal two-phase loop thermosiphon (HLTS) [4]. A study of heat pipes which was conducted by Anderson [5] showed that Dowtherm-A provides adequate thermal stability and compatibility with $304 \mathrm{SS}$ for $350^{\circ} \mathrm{C}$. Another study investigates that Dowtherm-A operates within temperature range $200-450^{\circ} \mathrm{C}$ in a wickless heat pipe with shell material of 316 SS [6].

\section{Heating Box System}

Polymer is transferred with jacketed transfer line which is covered by the heating box to maintain thermal stability of the system after extrusion process. In a standard operation, the heat generated by the meter pump is adequate to maintain operating temperature. When the meter pump is shut down, polymer would freeze in the unit without the heating jacket. For this reason the system needs a heat transfer medium to keep prefered temperature value of polymer.

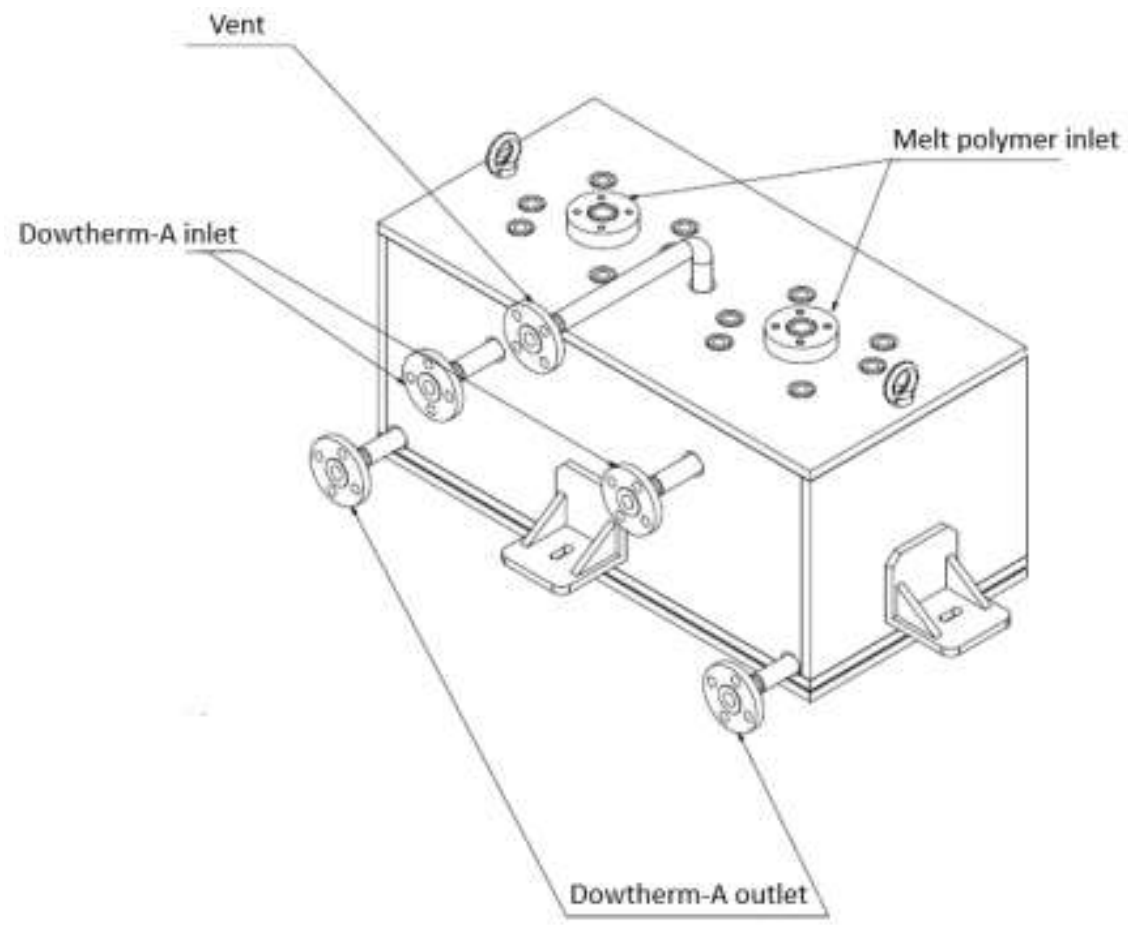

Fig. 1: Heating box schematic figure.

The heating process is done with vapor phase Dowtherm-A which enters from Dowtherm-A inlet to compensate the heat loss from the polymer as shown in Fig. 1. Dowtherm-A covers the inner volume of the heating box and condenses on the contact solid surfaces. The latent heat of Dowtherm-A is released during condensation and consequently the polymer temperature is kept at desired value. Incoming Dowtherm-A in heating box system entirely condenses and leaves from the Dowtherm-A outlet as liquid phase under the effect of gravity. Also, heating box has a vent line for unhandled exceptions. Temperature is controlled by adjusting Dowtherm-A pressure and a thermocouple measures Dowtherm-A fluid temperature instantly. High and low pressure alarms are integrated in the system. Fluid temperature and pressure values are monitored in the control rooms.

\section{CFD \& CHT Analysis}

CFD \& CHT analysis were performed for heating box system. Star CCM+ was utilized to model the CFD\&CHT simulation of heating box system. The heating box system is composed of gas phase Dowtherm-A inside the box, liquid phase of polymer inside the pipes, liquid phase Dowtherm-A on condensation surfaces and solid phase solidification chamber, pipes and insulation material in CFD model. 
Dowtherm-A enters the system as gas phase at saturation temperature of $300^{\circ} \mathrm{C}$. Condensation occurs in outer surfaces including pipes before and after pump, solidification chamber; inner surface of insulation where the temperature is lower than the saturation temperature of the Dowtherm-A. Several assumptions were made in CFD\&CHT analysis: 1) DowthermA in heating box system entirely condenses and leaves the box as liquid phase in transient analysis. 2) Since velocity of polymer is very low in solidification chamber, it was assumed that advection term is negligible. Therefore it was modelled as solid 3) Temperature change in pump and pipes outside of heating box was neglected. With these assumptions, 3-D CFD was generated as shown in

Fig. 2.
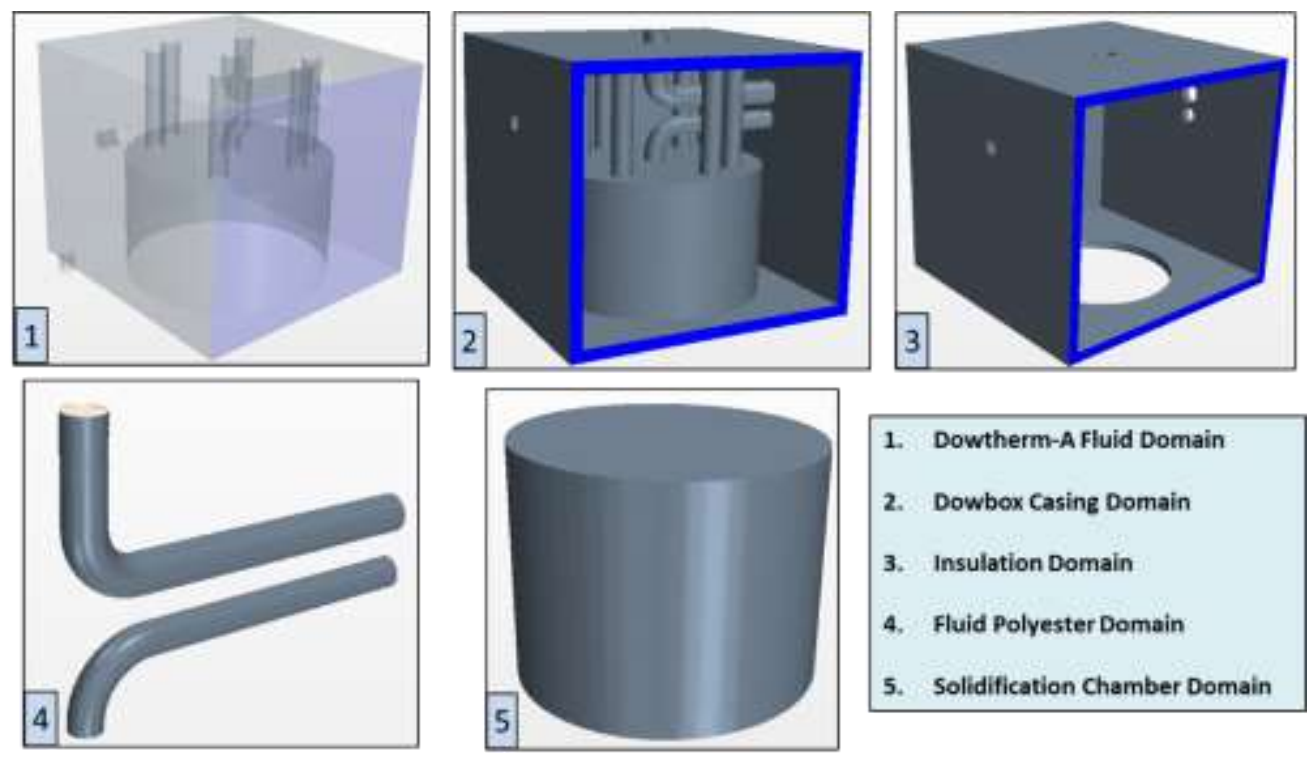

Fig. 2: Heating box system model details.

Firstly, steady state CFD analyses were performed to investigate the effect of inlet velocity to system. Condensation was not involved in steady state analyses. Secondly, the inlet mass flow is calculated for the heating box system which heat enters to system is equal to heat loss of system. With this calculation, polymer temperature is stabilized in transient CFD analyses and test system. Finally, transient CFD analyses were completed to include condensation in CFD models.

\subsection{Steady State Analysis}

Steady state CFD\&CHT analyses were performed for different inlet mass flow rate of Dowtherm-A. Results are illustrated for different mass flow rate in Fig. 3 below. Fluid tends to move polymer pipe with high energy in higher inlet mass flow rate cases. However, it loses its energy and faces towards solidification chamber for lower inlet mass flow as seen in Fig. 4. Fig. 5 compares the temperature distributions over the surfaces of the solidification chamber and the outer walls of the pipes which convey the fluid polymer. As seen the higher the mass flow of the gas phase Dowtherm-A is, the higher the temperature is. 

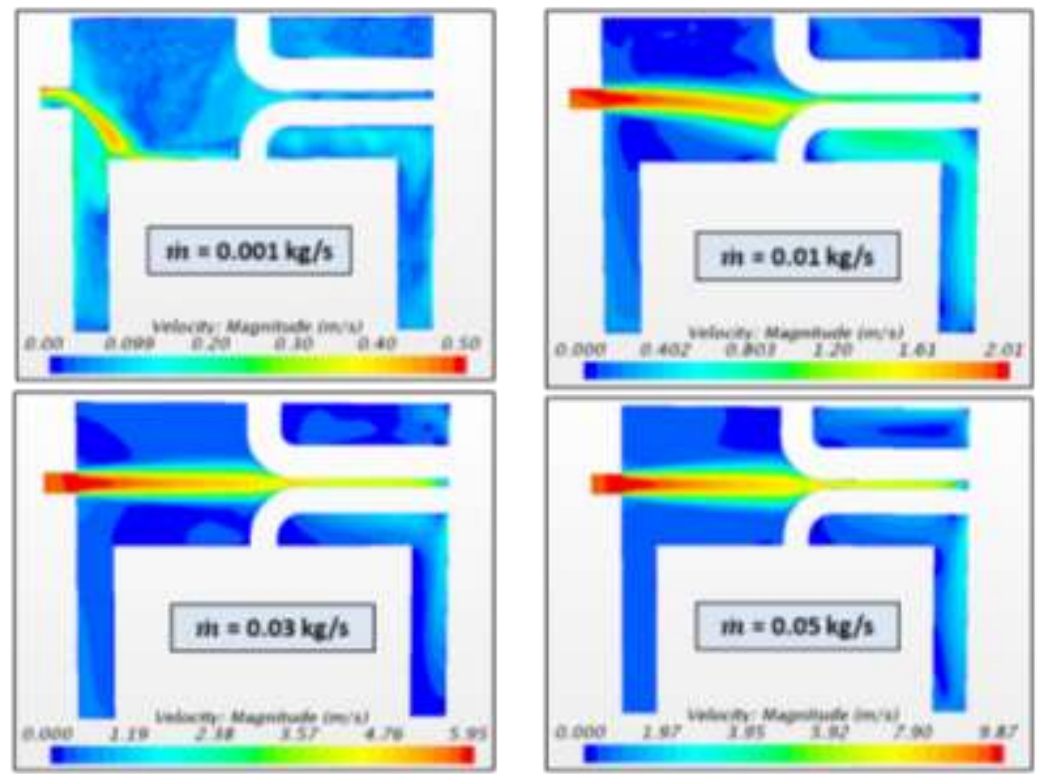

Fig. 3: Middle cross-section plane fluid velocity distribution for various inlet mass flow rate.
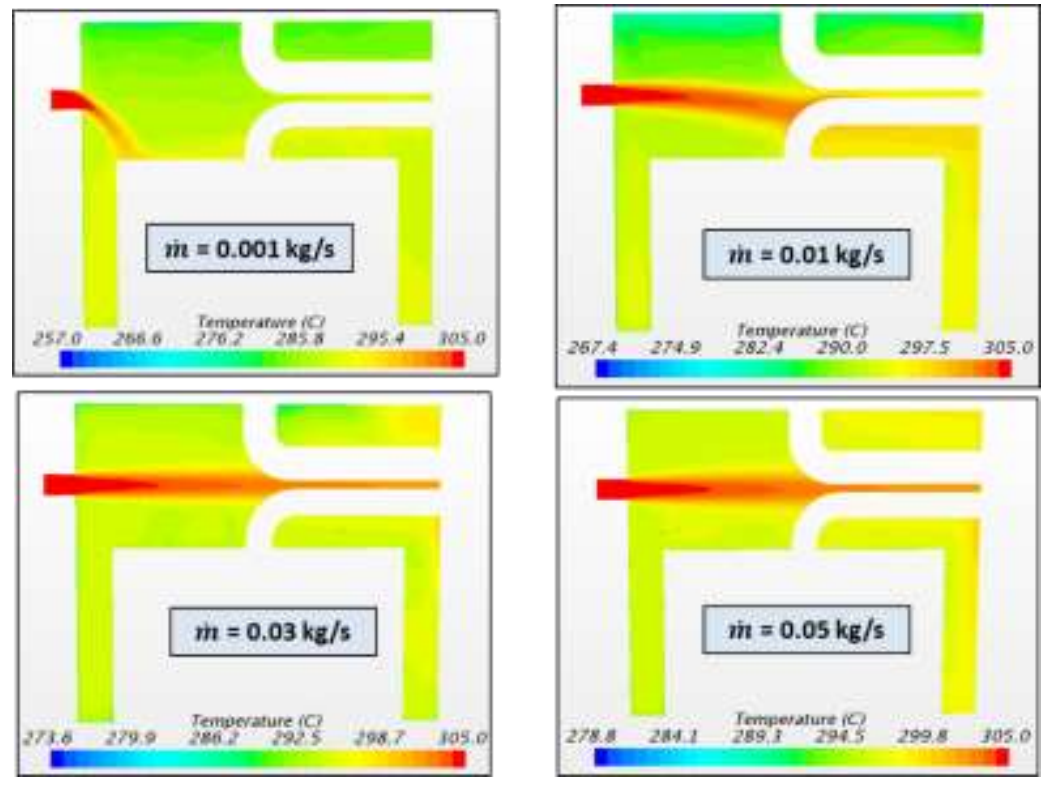

Fig. 4: Middle cross-section plane fluid temperature distribution for various inlet mass flow rate. 

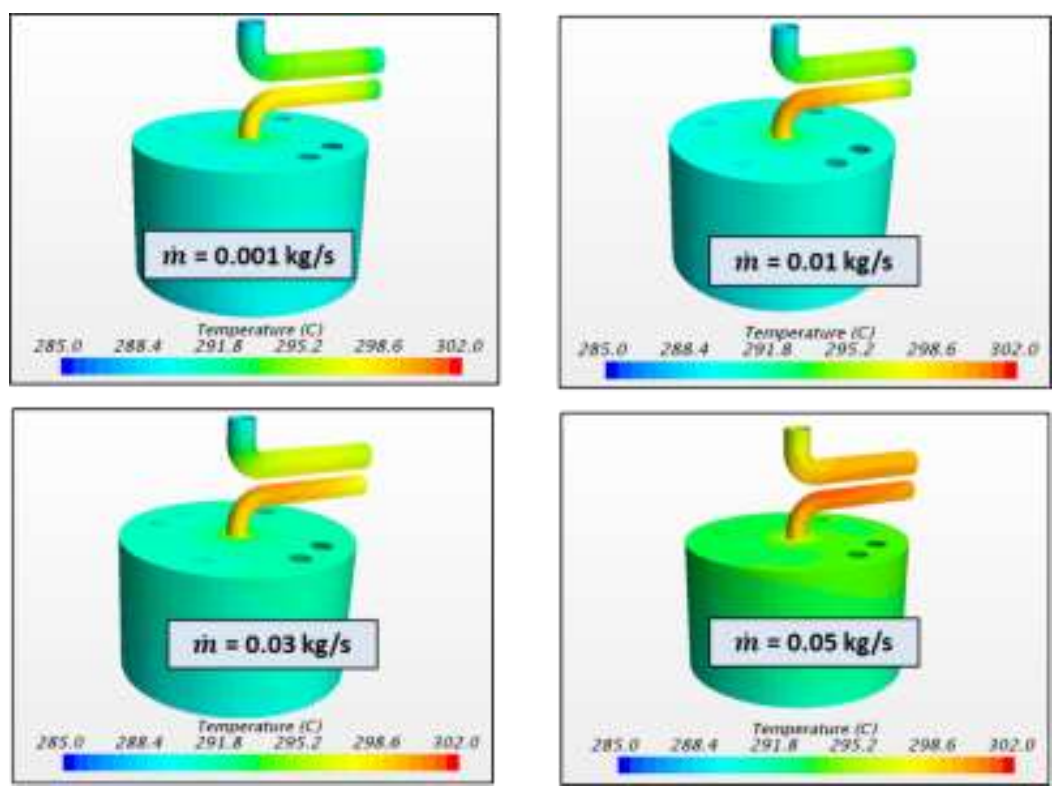

Fig. 5: Solid surfaces temperature distribution for various inlet mass flow rate.

\subsection{Inlet Mass Flow Calculation}

Mass flow inlet is calculated with respect heat loss of dow heating box system. Total heat loss of heating box is equal to temperature difference divided by equivalent resistance. Fig. 6 shows the heat transfer loss walls and their resistances due to convection and conduction.

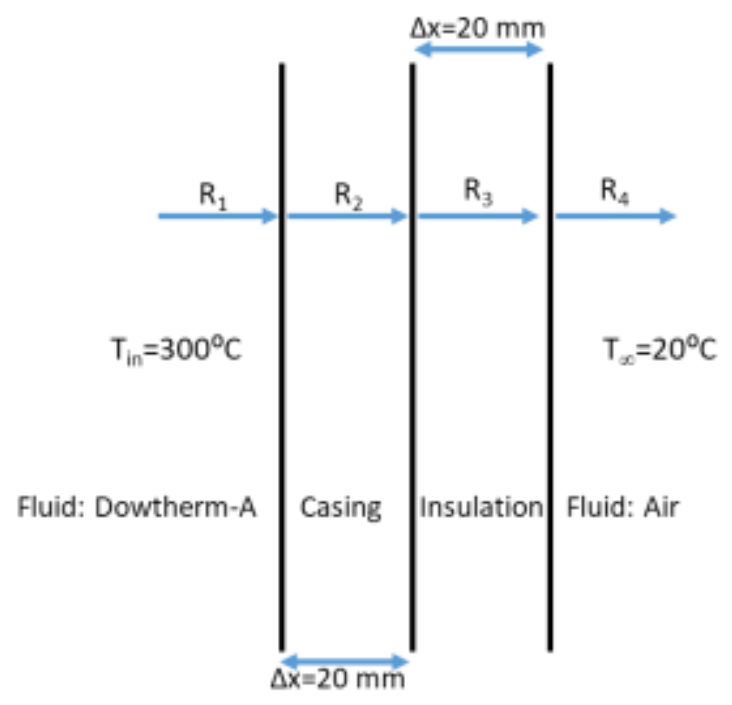

Fig. 6: Resistances in casing and insulation of heating box system.

Resistances were calculated with convection and conduction heat transfer in Eq (1):

$$
\begin{gathered}
\mathrm{R}_{1}=0 \quad \mathrm{R}_{2}=\frac{\mathrm{L}_{\text {casing }}}{\mathrm{k}_{\text {casing }} \mathrm{A}_{\text {casing }}} \quad \mathrm{R}_{3}=\frac{\mathrm{L}_{\text {insulation }}}{\mathrm{k}_{\text {insulation }} \mathrm{A}_{\text {insulation }}} \quad \mathrm{R}_{4}=\frac{1}{\mathrm{~h}_{\text {air }} \mathrm{A}_{\text {outer }}} \\
\mathrm{R}_{\text {eq }}=\mathrm{R}_{1}+\mathrm{R}_{2}+\mathrm{R}_{3}+\mathrm{R}_{4}
\end{gathered}
$$


Total heat loss was calculated as $\mathrm{Eq}(3)$ :

$$
\dot{Q}=\frac{\Delta \mathrm{T}}{\mathrm{R}_{e q}}
$$

\subsection{Transient Analysis with Condensation}

Total heat loss is calculated in Section 3.2. Required mass flow for heat equilibrium is calculated as $0.0035 \mathrm{~kg} / \mathrm{s}$ which is set as mass flow inlet boundary condition for transient analysis. The model consists of gas and liquid phase Dowtherm-A, liquid phase polymer and solid phase heating box casing, insulation and solidification chamber domains. Fig. 7 shows the boundary conditions for transient analysis. Liquid phase polymer enters the system with before-pump pipe and a pressure outlet is defined at the exit of before-pump pipe. Liquid phase polymer re-enters the system via afterpump pipe at higher pressure level. A mass flow outlet is set at the exit of the after-pump pipe.

\section{Transient CFD \& CHT Modeling Geometry \& Boundary Conditions}
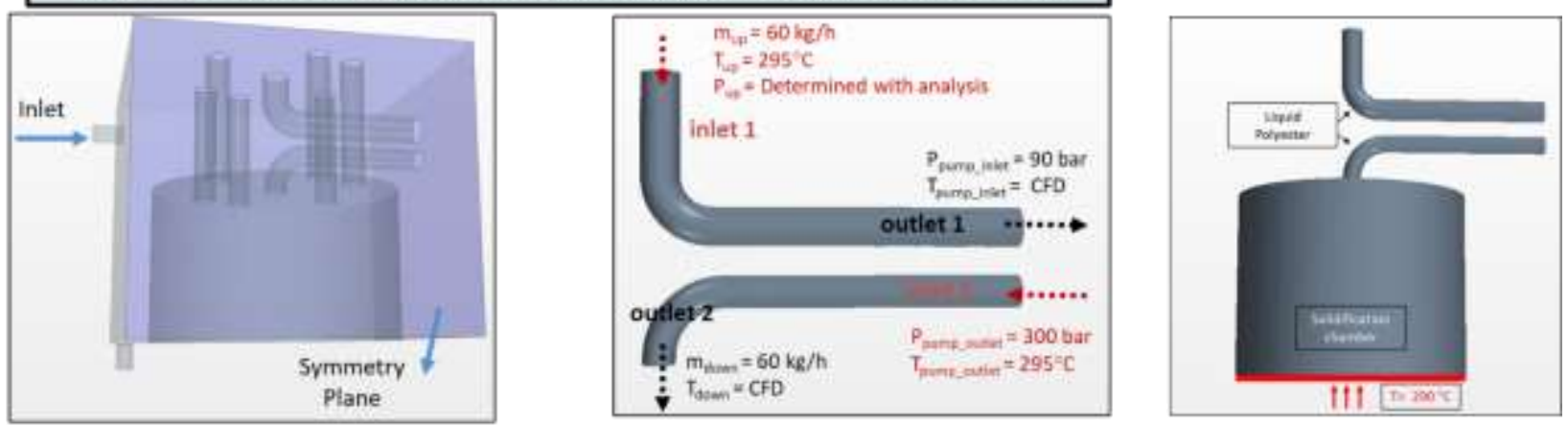

Fig. 7: Boundary conditions of transient analysis.

Green lines and surfaces in Fig. 8 show the surfaces of the casing walls, solidification chamber, pipes and stud bolts where the condensation of gas phase Dowtherm-A takes place. After condensation starts in the simulation, the shown surfaces are covered with liquid phase Dowtherm-A.
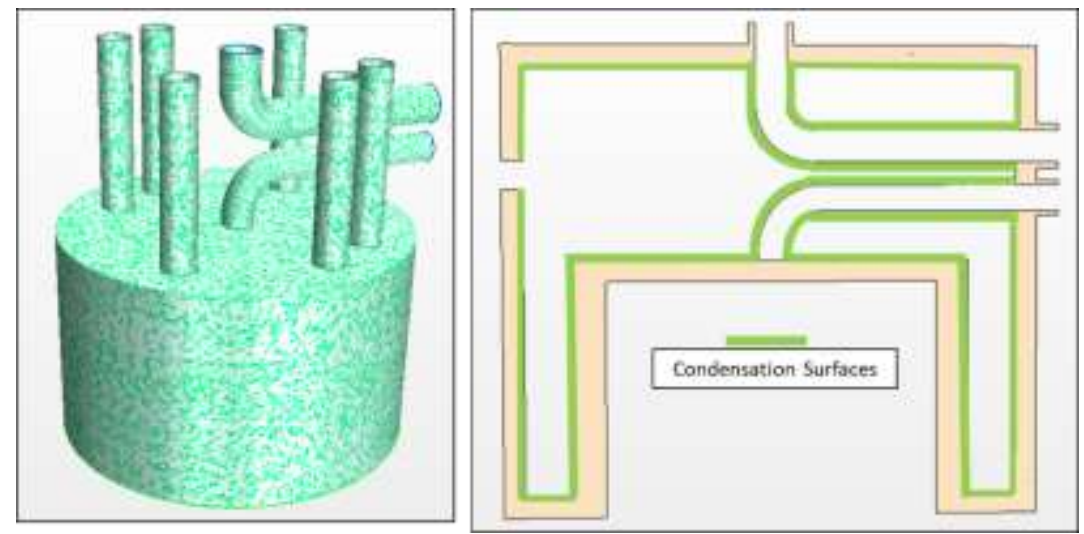

Fig. 8: Dowtherm-A condensation surfaces.

Dowtherm-A condenses on surfaces and film thickness increases at higher condensation rates. In order to understand the effect of fluid film thickness, two different solidification chamber designs were analyzed. Design 1 is the base design which has a flat top surface of solidification chamber. Since, previous studies showed that two-phase Dowtherm-A heat transfer performance increased by inclination [4], Design 2 has a solidification chamber with an inclined top surface as 
shown in Fig. 9. It is expected that, the inclined surface of Design 2 would let the fluid film quickly flows down from the top surface of the solidification chamber and eventually the heat transfer performance would increase.
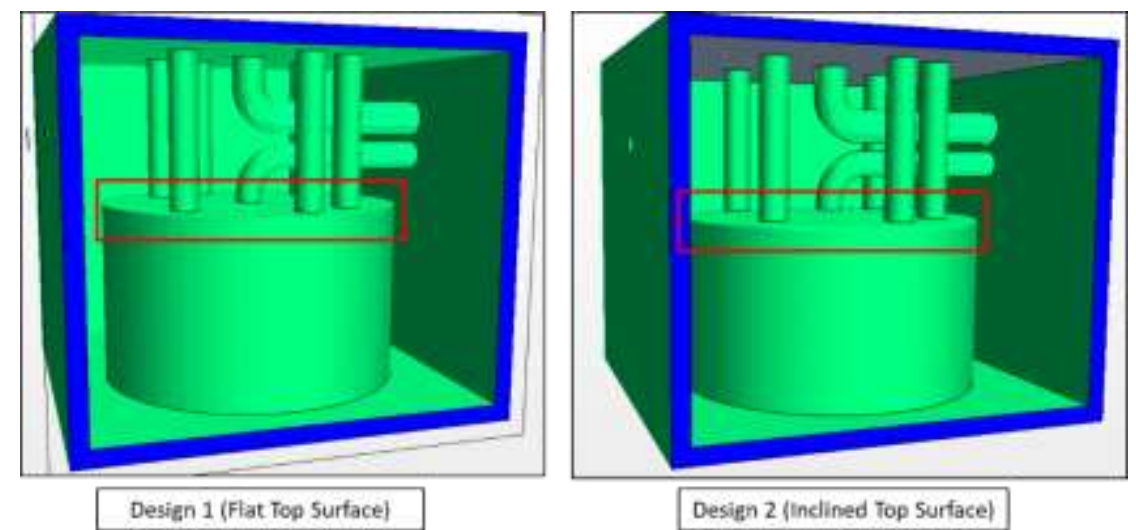

Fig. 9: Design $1 \&$ Design 2 geometry models.

CFD\&CHT results for Design 1 and Design 2 are illustrated in Fig. 10-Fig. 15. In Fig. 10, accumulation of the condensed film on the top surface is higher for the flat top design. Inclination on solidification chamber top surface facilitates the removal process of the accumulated condensed fluid film on the top of the solidification chamber. Therefore, Design 2 has lower fluid film thickness on top surface in comparison to Design 1.

Fig. 11 compares the heat transfer of solidification chamber for Design 1 and Design 2. Since the fluid film thickness acts as an insulator over the condensation surfaces, it mitigates the heat transfer as it thickens. Removing the fluid film from the heat transfer surfaces increase the heat transfer process rate. Therefore, heat transfer rate on solidification chamber of Design 2 is $3.5 \%$ higher than Design 1. Fig. 12 shows that approximately half of the total heat transfer takes place towards solidification chamber and polymer pipes, while the other half is lost due to heat transfer with ambient air.

In Fig. 13, since removing the accumulated condensed fluid film from the top surface increases the heat transfer, temperature values are higher on the top surface for Design 2. Fig. 14 and Fig. 15 show vertical and radial sections from the solidification chamber respectively. As seen, the temperature distribution reaches higher values for Design 2.
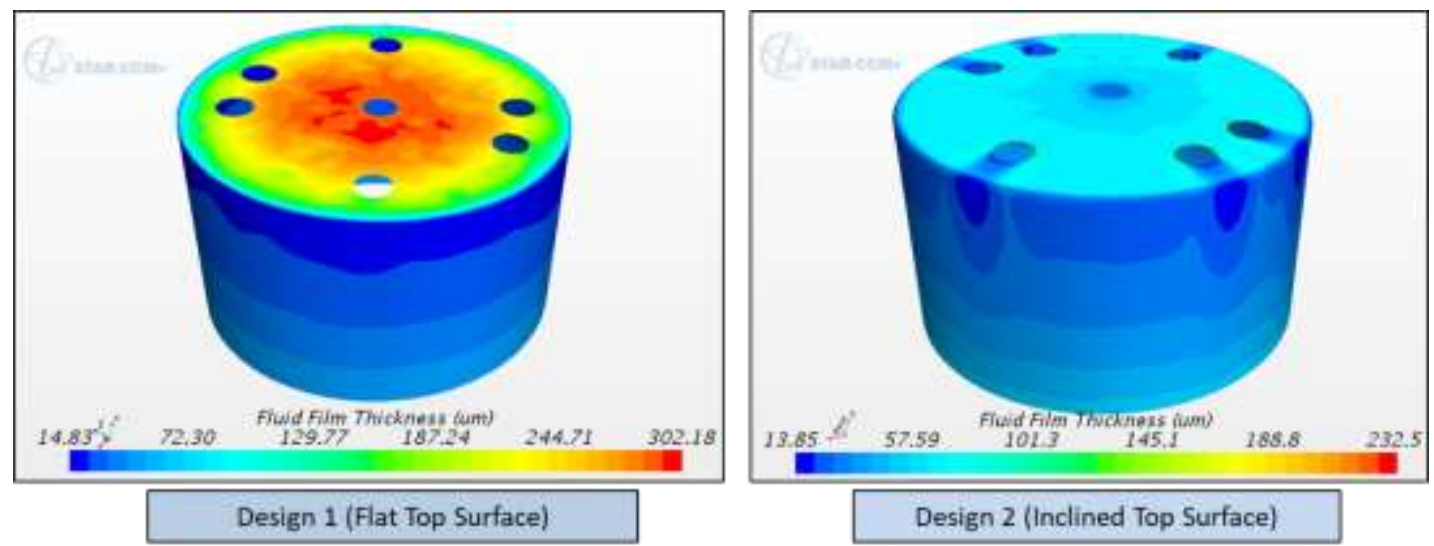

Fig. 10: Fluid film thickness comparison for Design 1 \& Design 2. 


\begin{tabular}{|c|c|c|}
\hline $\begin{array}{c}\text { Top Surface } \\
\text { Design }\end{array}$ & Flat Top Surface & Inclined Top Surface \\
\hline & Heat Transfer (W) & Heat Transfer (W) \\
\hline & 445 & 461 \\
\hline
\end{tabular}

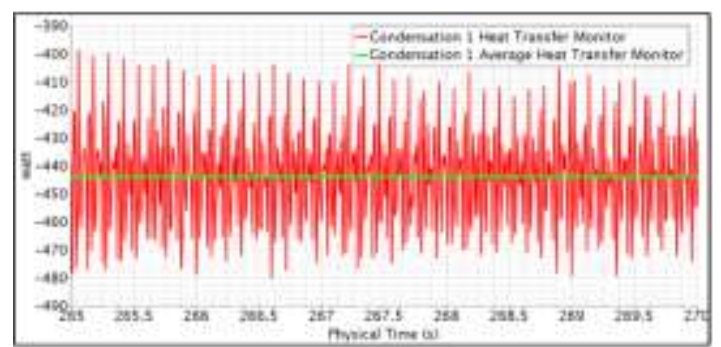

Design 1 (Flat Top Surface) Heat Transfer

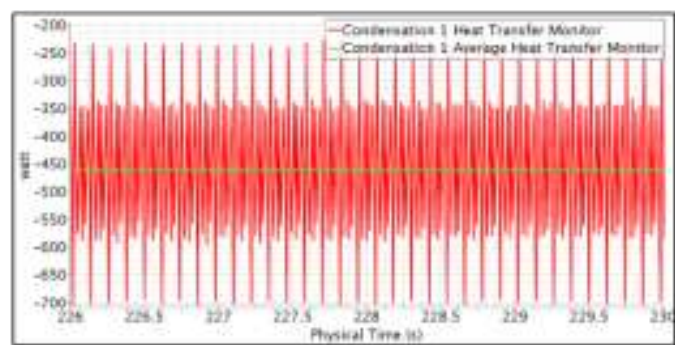

Design 2 (inclined Top Surface) Heat Transfer

Fig. 11: Heat transfer comparison of solidification chamber for Design $1 \&$ Design 2.

\begin{tabular}{|c|c|c|}
\hline Location & $\begin{array}{c}\text { Heat } \\
\text { Transfer } \\
(\mathrm{W})\end{array}$ & $\begin{array}{c}\text { Heat } \\
\text { Transfer } \\
(\%)\end{array}$ \\
\hline 1 & 461 & 46.1 \\
\hline 2 & 17 & 1.7 \\
\hline 3 & 17 & 1.7 \\
\hline 4 & 5 & 0.50 \\
\hline 5 & 508 & 50 \\
\hline Total & 1008 & \\
\hline & & \\
\hline
\end{tabular}
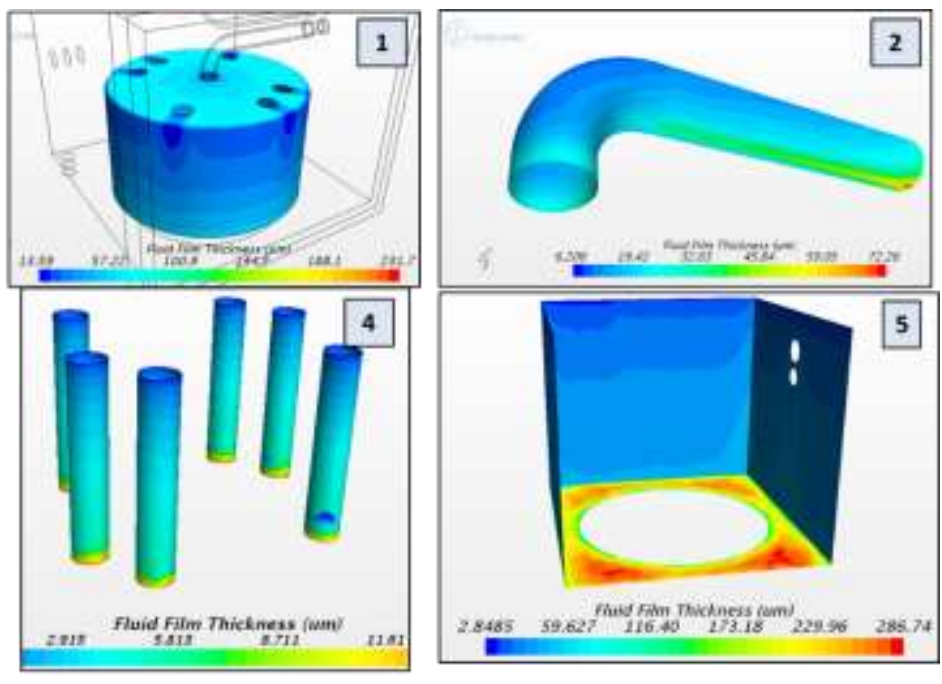

Fig. 12: Heat transfer rate for components of heating box (Design 2). 


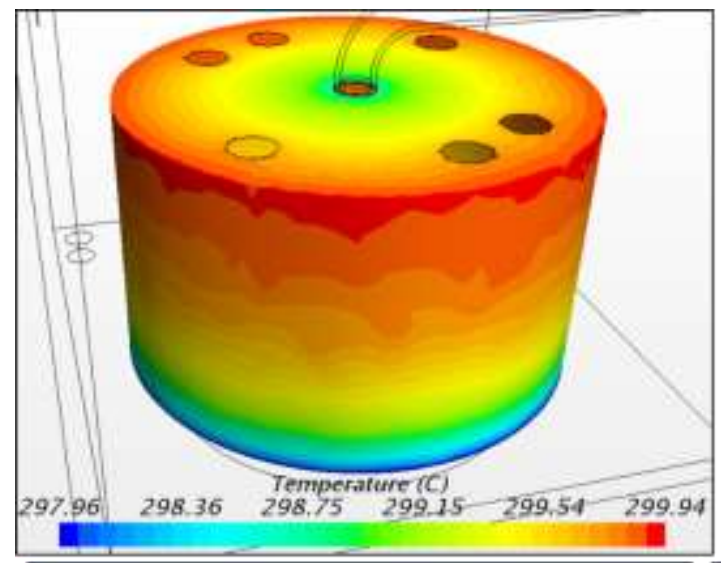

Temperature Distribution for Design 1 (Flat Top Surface)

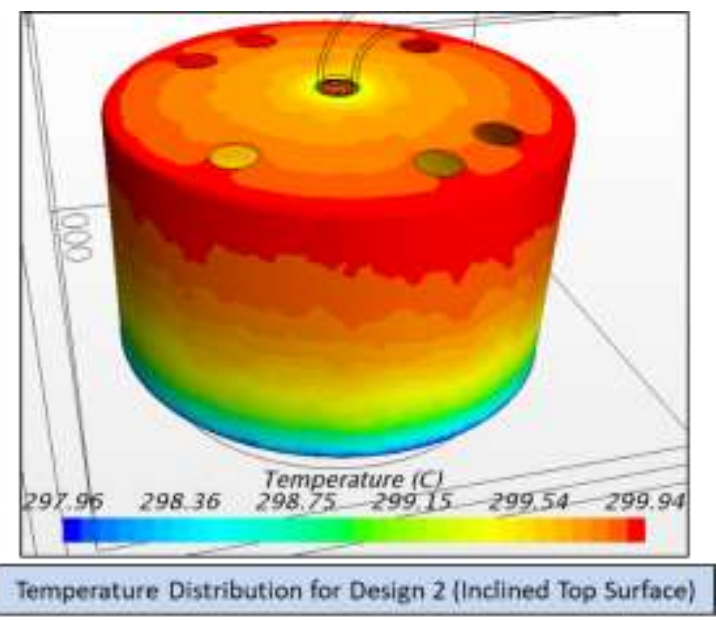

Temperature Distribution for Design 2 (Inelined Top Surface)

Fig. 13: Temperature distribution comparison of solidification chamber for Design 1 \& Design 2.

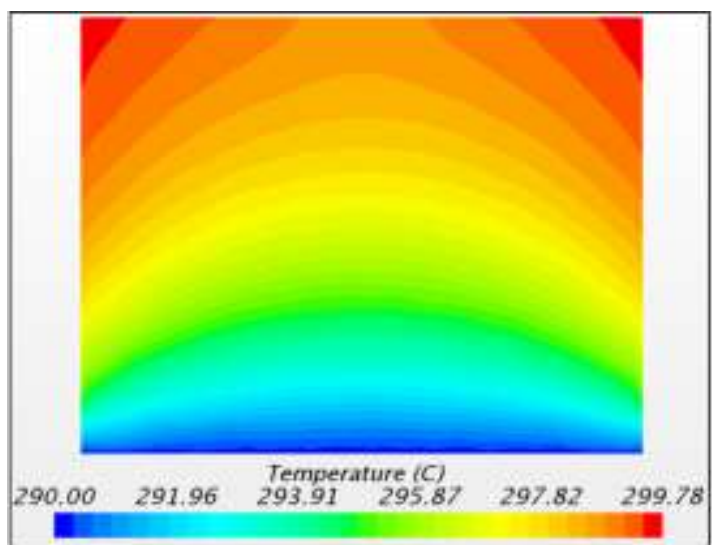

Temperature Distribution of Middle Cross-Section Plane of Solidification Chamber for Design 1 (Flat Top Surface)

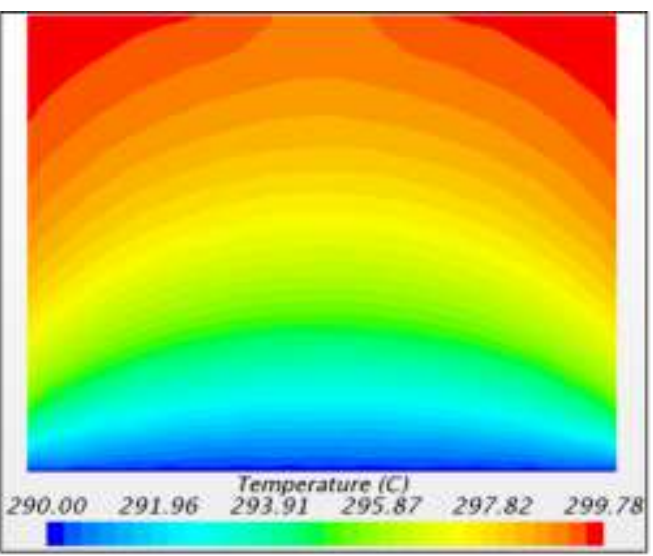

Temperature Distribution of Middle Cross-Section Plane of Solidification Chamber for Design 2 (Inclined Top Surface)

Fig. 14: Temperature distribution comparison of longwise middle cross-section plane of solidification chamber for Design $1 \&$ Design 2.

Fig. 16 shows the heat flux distribution over the top surface of the solidification chamber of Design 1 and Design 2. Since the inclination facilitates the removing process rate of the condensed fluid film from the top surface of the solidification chamber the fluid film thickness is lower for Design 2. Thus, the heat resistance of the fluid film is lower for Design 2 and consequently heat flux values are higher compared to Design 1. 


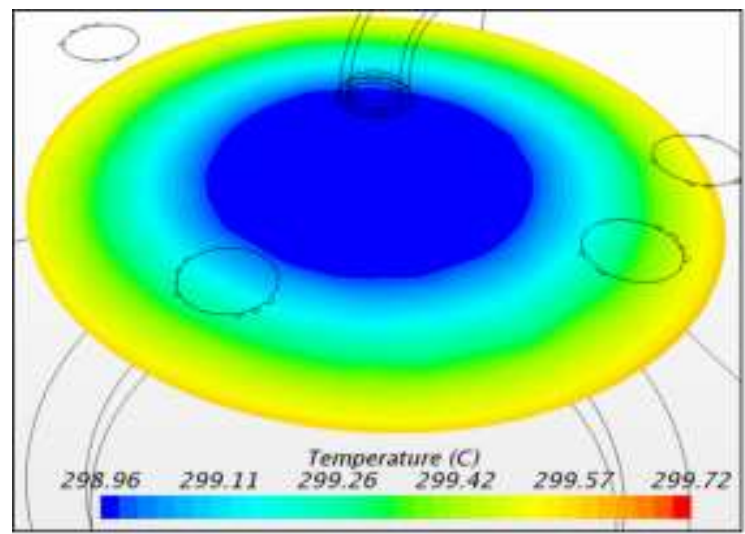

A Radial Cross-Section Plane Temperature Distribution for Design 1 (Flat Top Surface)

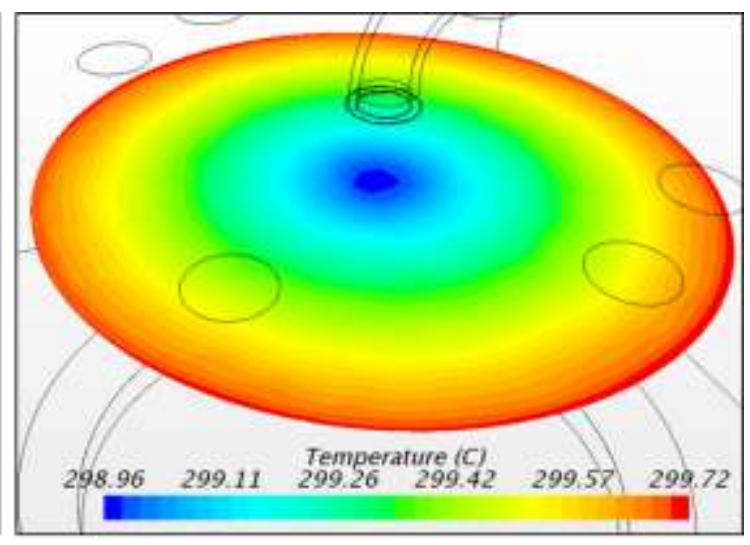

A Radial Cross-Section Plane Temperature Distribution for Design 2 (Inclined Top Surface)

Fig. 15: Temperature distribution comparison of a radial cross-section plane of solidification chamber for Design 1 \& Design 2.
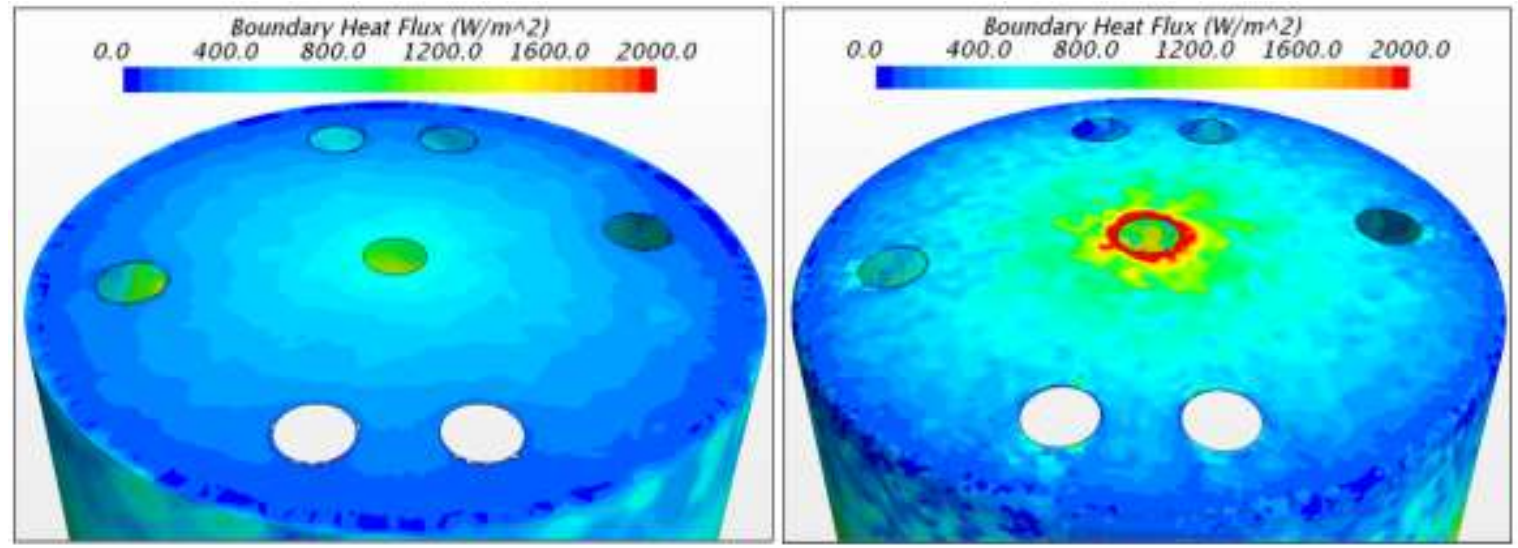

Fig. 16: Heat flux distribution comparison of top surface of solidification chamber for Design $1 \&$ Design 2.

\section{Conclusion}

In this paper the effect of inclination top surface of solidification chamber was investigated with two different dow heating box designs. Results show that inclined top surface remove more fluid from top surface and decreases fluid film thickness. Lower fluid film thickness increases heat transfer rate. Therefore, heat transfer rate of solidification chamber of Design 2 is $\% 3.5$ higher than Design 1. It is also investigated that approximately $\% 50$ of the heat is transferred to solidification chamber and polymer pipes whereas another half of the heat is lost due to heat transfer with ambient air. Total heat transfer is 1008 Watt for the dow heat box.

In steady state cases, fluid moves toward polymer pipe with high energy in higher inlet mass flow rate cases. However, it loses its energy and faces towards solidification chamber.

Required Dowtherm-A mass flow for heat equilibrium is calculated $0.0035 \mathrm{~kg} / \mathrm{s}$ for this system. It is defined as mass flow inlet for transient analysis. Therefore, heating box reaches a steady state equilibrium at approximately $300^{\circ} \mathrm{C}$ for transient analysis.

\section{Acknowledgements}

The authors would like to acknowledge Kordsa and SDM R\&D companies for their supports. Special thanks to Erhan Atay for the support. We express our thanks to Dr. Ertugrul Tolga Duran for his time and feedback. 


\section{References}

[1] "Dowtherm-A Heat Transfer Fluid-A Product Technical Data," Dow Chemical Company, USA, 1997.

[2] F. P. Incropera, D. P. DeWitt, T. L. Bergman, A. S. Lavine, Fundamentals of Heat and Mass Transfer, $6^{\text {th }}$ Edition.

[3] A. Faghri, "Heat Pipe Science and Technology," Taylor\&Francis, 1995.

[4] Y. Wang, X. Wang, H. Chen, H. Fan, R. A. Taylor, Y. Zhu, "CFD Simulation of an Intermediate Temperature, Twophase Loop Thermosiphon for Use as a Linear Focus Solar Receiver," Energy Procedia, vol. 105, pp. 230 - 236, 2017.

[5] William G. Anderson, Sanjida Tamanna, Calin Tarau, and John R. Hartenstine, "Intermediate temperature fluids life tests-experiments," in Proceedings of the 16 ${ }^{\text {th }}$ International Heat Pipe Conference, Lyon, France, 2012.

[6] H. Jouhara, A. J. Robinson, "An experimental study of small-diameter wickless heat pipes operating in the temperature range $200^{\circ} \mathrm{C}$ to $450^{\circ} \mathrm{C}$," Heat Transfer Engineering, vol. 30, pp. 1041-1048, 2009. 